\title{
Review and Prospect of the Measurement and Application of Human Capital*
}

\author{
Lan Ma \\ School of Statistics and Mathematics \\ Zhongnan University of Economics and Law \\ Wuhan, China
}

\begin{abstract}
This paper first organizes the development process of human capital theory and the improvement process of the definition of human capital, emphasizing the importance of human capital in economic and social development, then summarizes the existing methods of human capital measurement and existing defects. After that, it discusses the application of human capital from two perspectives of economic growth and technological innovation. It is concluded that human capital is one of the important factors of economic growth and can explain individual differences. It is imperative to incorporate human capital into the national accounts system. It points out that the study of urban human capital is a hot spot. It's necessary to pay attention to the relationship between human capital informationization and enterprise innovation, and prospects for future research.
\end{abstract}

Keywords-human capital; measurement; application research; review; expectation

\section{INTRODUCTION}

Since the birth of human capital theory in the 1960s, many scholars have begun to study this field. Similar to the physical capital, human capital is also an important source of economic growth. In this information age, human capital has exceeded physical capital. Paying attention to human capital and the "tussle for talent" is one of the competition methods of all walks of life.

The concept of human capital was proposed by the American economist Schultz (1961), followed by Becker (1960, 1964), Denison (1961), and Romer (1986, 1990). Lucas $(1967,1988)$ and others have further expanded and extended the theory and application of it. Schultz pointed out that human capital is the knowledge, skills and health of people, and that is the ability to work in society. Posterity further pointed out that human capital is formed through education, training, migration, medical security and other forms. Economic growth is one of the main factors, also the determinant factor of individual differences. Later, the unified version was defined as the combination of the various capabilities formed by human capital investment and condensed on the human, which can bring the expected benefits and economic benefits. The access to human capital includes: school education, on-the-job training, population

*Project: Graduate Research and Innovation Project of Zhongnan University of Economics and Law, Project No.: 201811307. migration, health care, etc. School education is the main way of human capital investment among them.

It's important to clarify the concept of human capital in the study of modern economic growth and labor employment theory. On the one hand, human capital stock and its growth are important factors in social economic growth in the knowledge economy age. On the other hand, studying the differences in individual human capital can explain the individual ability differences and income gap. It can be seen that human capital is a powerful tool for modern economic and social analysis, which requires continuous improvement and improvement in the research and measurement of human capital. Therefore, human capital is an important analytical tool both at the macro level and micro level. This also means that the reasonable calculation of human capital has important practical significance and academic value.

Next, the existing research on human capital will be sorted out in two directions: one is the measurement method of human capital, and the other is the application field of human capital.

\section{The Calculation Method of Human CAPITAL}

At present, the more commonly accepted calculating methods of human capital measurement include the income method, the cost method, and the education index method. Many scholars in China use the income method to study human capital, such as Zhu Pingfang (2007), Li Haizheng (2015). Qian Xueya (2005), and Qiao Hongfang (2015) and some people used the cost method to measure China's human capital. Because of the limitation of data availability, more scholars have chosen to adopt the educational index method and use the education years as a measure index of human capital. The theoretical knowledge, indicator system, and data support used by different measurement methods are inconsistent, which also leads to large differences in the results of the measurements. Therefore, the estimation of human capital is a major problem in today's social economy.

Kendrick (1976) and Eisner (1985) use the perpetual inventory method to measure the value of human capital is more comprehensive and systematic, but the method adopted by the two is similar to the estimation of physical capital, so it is not strictly human capital accounting; The required human capital accounting is a method by Jorgenson and 
Fraaumini use expected returns to estimate the US human capital stock and propose a new US national economic accounting system. It analyzes the role of capital in economic growth and compares human capital with nonhuman capital investment. It was finally discovered that in the United States, the role of human capital has exceeded physical capital.

Many scholars have improved the previous research methods and obtained better estimation results. From the perspective of expected income, Jorgenson and Fraumeni measured the human capital stock and price in the United States from 1948 to 1984 . Li Haizheng and other scholars (2010) used the existing accounting data to improve the lifetime income method proposed by Jorgenson-Fraumeni, and calculated the total human capital in China from 1985 to 2007; the innovation put forward the human capital index and calculated the corresponding data. Yao Yang and Cui Jingyuan (2015) continue to conduct in-depth research on the basis of the Education Indicators Act, taking into account the rate of return on education and using it as the weight of year's education. Previous studies have rarely involved the return of education, and it turns out that the research results of this method are better.

There are few types of domestic human capital data now, which is the biggest obstacle to the advancement of human capital research. Therefore, some scholars advocate the inclusion of human capital in the national economic accounting system. Xu Yingmei (1999) expounded the concept of human resources and human capital, calculated the flow and stock of human capital, and finally proposed to introduce human capital into the current national economic accounting framework; Wang Dejin (2008) pointed out that China's human capital accounting failed to consider the depreciation and price factors that are mainly due to the inability to obtain data. It is further pointed out that human capital is included in the national economic accounting, which provides a data base for further research on human capital. In order to give full play to the role of human capital in the economic field and to achieve further breakthroughs, it is imperative to incorporate it into the National Account System (SNA).

In the knowledge economy age now, information technology continues to develop. In order to keep up with the times, workers need to constantly learn and expand themselves, so "learning by doing" is more profound now. However, the rapid update of information technology has made the difficulty of "dry middle school" increase, and the depreciation rate of human capital has also increased. At present, in the study of measuring human capital stock, the factors of depreciation of human capital are less considered. Shan Haojie (2008) comparatively analyzed the research on capital stock in the existing literature, summarized the shortcomings of the calculation methods, and reconstructed four important indicators of capital stock, especially the calculation of the base period capital stock and depreciation rate. It provides the basic data for the follow-up research. When measuring the stock of human capital, it is a good research direction to continue to examine the impact of the depreciation rate of human capital.

\section{THE APPLICATION OF HUMAN CAPITAL}

In the new economic theory, human capital is an important factor in economic growth. The Solow growth model, the Lucas model, and the "learning by doing" doctrine are the theoretical basis. Nowadays, the role of social and economic development is getting bigger and bigger, and its applications continue to expand. Some scholars have studied the role of human capital from the perspectives of economic growth, enterprise innovation (involving high-quality talents), total factor production, and regional economic development. This paper selects two perspectives of economic growth and technological innovation to study the role and mechanism of human capital.

\section{A. Research Status of the Relationship Between Human Capital and Economic Growth}

The main paths of human capital investment include education, training, health, and migration. Influenced by the availability of data and actual practical significance, most scholars choose to use the two indicators of education and health to study the mechanism of human capital investment on the economy. Ni Chao (2016) uses the two factors of education and health, combined with the panel data of 65 countries from 1995 to 2013, to measure the contribution of human capital to economic growth of various types and regions.

Some scholars are studying the role of education human capital in the economy now. Barro and Martin (1995) found that the average years of schooling had a positive effect on economic growth in earlier times. Vandenbussche and some scholars (2006) studied the role of human capital in total factor productivity and found that people with higher education promoted the role of total factor productivity, but the role of primary education was not obvious. Zheng Ming and Zhu Huaizhen (2007) found different conclusions in China. Higher education hindered the development of the local economy after the enrollment expansion of colleges and universities. Barro (2013) began research on the gender aspects of educational human capital and found that adult men's secondary school education and above are positively related to economic growth, but adult women of the same educational nature are not related to economic development; in addition, the effect of men's basic years education on the economy is not obvious. Chao Ni and some scholars (2015) analyzed the panel data of 30 provinces in China from 2000 to 2013 found that the human capital of undergraduate and above significantly promoted economic growth, but the correlation between specialist education and economic growth was still uncertain.

Some scholars have also studied the role of health in human capital. Grossman (1972) proposed that health is an important component of human capital. The health level of a country's residents plays an important role in economic growth; Barro (1996) and Zhang Chewei (2003) have found that health levels promote economic growth; later, some scholars discovered that the promotion of health to economic growth is divided into several stages. At the beginning, the increase of healthy human capital can promote economic 
growth. However, when it comes to a certain level, its promotion to the economy gradually weakens and disappears.

Some scholars have combined education and health to discuss the effects of human capital on economic investment: Kesikoglu and Zafer (2013) used panel data from 1999 to 2008 in 20 OECD countries, and tested: education costs and health care expenditures have a two-way causal link with economic development. Yu Changlin (2006) found that human capital's education investment and health investment have significantly promoted economic growth. Chu Chengbing and Li Ping (2014) found that education has a significant role in promoting economic growth, but the health investment has a non-significant effect on economic promotion.

\section{B. Research Status of the Relationship Between Human Capital and Technological Innovation}

At present, some scholars explore the role of human capital in SME development and technological innovation. Zhang Yuming and Liu Desheng (2010) studied the growth mechanism of small and medium-sized technology enterprises from the perspective of corporate culture and human resources, and found that human resources have a positive effect on the growth and competitiveness of small and medium-sized enterprises.

In the existing research, some scholars explore the relationship between informationization, innovation development and human capital. Bresnahan et al. (2002) believe that the development of informatization can promote the investment of human capital; Wang et al. (2006) found that the development of enterprise informatization has a significant role in promoting the development of human capital; Yao Dongjun et al (2017) believe that human capital is promoted Important factors of innovation and technology; Ning Guangjie and Lin Ziliang (2014) examine the relationship between informationization and employment from the perspective of skills, and believe that the development of information technology leads to the income growth and social demand of high-tech talents. In this way, the informationization of society can increase the stock of high-tech human capital.

Some scholars have found that human capital plays a mediating role between informatization and innovation. For example, Zhang Wei and Li Changying (2019) examined the effect of human capital on the innovation of regional economy and examined the intermediary role of human capital in the two. The results show that the intermediary role of human capital has nonlinear characteristics, and informationization has a significant effect on innovation development and human capital, and presents an inverted Ushaped feature. Li Linhan and Tian Weimin (2019) analyzed that human capital plays a mediating role between science and technology finance and technological innovation. With the improvement of human capital level in a region, scientific research plays a more and more important role in technological innovation.

\section{CONCLUSION}

This paper draws the following conclusions by summarizing the existing research on combing human capital:

First of all, human capital is a manifestation of human intelligence, physical strength and health, which can explain the individual differences of different people. The biggest problem in the current measurement of human capital is that the data is difficult to obtain. Therefore, this paper once again proposes to incorporate human capital into the national economic accounting system based on the previous research; the current depreciation of human capital has not been thoroughly studied, and it is possible to continue to examine the calculation about the depreciation rate of human capital.

Secondly, the existing research cares more about the promotion of its economy from education and health in the application field of human capital and economic growth. Human capital can now be decomposed into four factors: education, health, training, and migration. Spatial measurement is used to study the relationship between various factors and the economy. The measurement range of human capital is mainly at the national and regional levels now, and there are few studies on urban human capital. However, cities are the main form of modern life. At present, economic competition and talent competition between cities are fierce. Therefore, focusing on human capital with urban research is a hot spot.

Thirdly, many scholars have concluded that human capital plays a mediating role between social informationization and innovation development, but this intermediary role still worth further exploration. There may also be a nonlinear relationship between human capital and informatization from past experience. First, with the rapid development of informatization, human capital has been improved through "dry middle school" and employment training; secondly, the input of informationization has a marginal diminishing phenomenon. After the informationization is invested to a certain extent, it is likely to crowd out the investment of human capital. In this way, if the informationization is not used properly, it will cause damage to the development of human capital. Therefore, when studying the fields of informatization and regional innovation in combination with China's reality, it is of great practical significance and academic value to attach importance to the intermediary role of human capital.

\section{REFERENCES}

[1] Schultz, T. W. Investment in Human Capital, American Economic Review, 1961.51(1), (March):1 - 17.

[2] Becker, G. S. Human Capital (2nd ed), The University of Chicago Press, 1975.

[3] Denison E F. Measurement of Labor Input: Some Questions of Definition and the Adequacy of Data [J]. Nber Chapters, 1961.

[4] Romer, P. M . "Increasing Returns and Long-run Growth" , Journal of Political Economy, 1986. 94.

[5] Lucas, R. E. On the Mechanics of Economic Development, Journal of Monetary Economics, 1988. 22:3-42.

[6] Zhu Pingfang, Xu Dafeng. Estimation of Human Capital in Chinese Cities [J]. Economic Research, 2007 (9): 84-95. (in Chinese) 
[7] Li Haizhen, Tang Tang. Regional Differences of Labor Quality Based on Human Capital [J]. Journal of Central University of Finance and Economics, 2015(08): 72-80+86. (in Chinese)

[8] Qian Xueya. A Reasonable Perspective on Human Capital Stock Measurement [J]. Zhejiang Social Sciences, 2005(05): 43-47. (in Chinese)

[9] Zhang Zhaojun, Zhao Hongzhong. Estimation of China's Human Capital Stock [J]. Statistical Research, 2012, 29(06): 41-45. (in Chinese)

[10] Qiao Hongfang, Shen Lisheng. Re-estimation of China's Human Capital Stock: 1978-2011 [J]. Shanghai Economic Research, 2015 (07): 36-45. (in Chinese)

[11] Kendrick, J., 1976, The Formation and Stocks of Total Capital, Columbia University Press, New York, N.Y.

[12] Eisner, Robert, 1989, The Total Incomes System of Accounts, The University of Chicago Press, Chicago.

[13] Jorgenson, Dale W.and Barbara M .Fraumeni, 1989, "The Accumulation of Human and Non-human Capital, 1948-1984", in R.Lipsey and H.Tice eds., The Measurement of Saving, Investment and Wealth, Chicago, University of Chicago Press.

[14] Jorgenson D W, Fraumeni B M. Investment in education and US economic growth [J]. The Scandinavian Journal of Economics, 1992: S51-S70.

[15] Li Haizhen, Liang Yunling, Barbara Fraumeni, et al. China Human Capital Measurement and Index Construction [J]. Economic Research, 2010(8): 42-54. (in Chinese)

[16] Yao Yang, Cui Jingyuan. Research on the Measurement of Human Capital in China[J]. Chinese Journal of Population Science, 2015(1): 70-78.(in Chinese)

[17] $\mathrm{Xu}$ Yingmei. The introduction of human capital into the current SNA research [J]. Statistical Research, 1999 (S1): 91-94.(in Chinese)

[18] Wang Dejin. A Summary of the Research on Human Capital Incorporated into National Economic Accounting[J]. Journal of Statistics \& Information, 2008, 23(8): 86-91.(in Chinese)

[19] Shan Haojie. Re-estimation of China's Capital Stock K: 1952-2006 [J]. Journal of Quantitative and Technical Economics, 2008(10): 17-31.

[20] Ni Chao. Research on the Investment Effect of Human Capital on Economic Growth - An Empirical Test Based on Panel Data of 65 Countries [J]. China Human Resources Development, 2016(15): 8796. (in Chinese)

[21] Barro, R. and Salai Martin X. Economic Growth, NewYork: Mc Graw Hill, 1995.

[22] Vandenbussche J, Aghio P, Meghir C. Growth, Distance to Frontier and Composition of Human Capital. Journal of Economic Growth, 2006, 11(2):97-127.

[23] Zheng Ming, Zhu Huaizhen. Higher Education and Regional Economic Growth - An Empirical Study Based on Chinese Provincial Panel Data [J]. Education Research of Tsinghua University, 2007(04): 76-81. (in Chinese)

[24] Barro RJ. Education and Economic Growth. Cema Working Papers, 2013,14(2):277-304

[25] Chao Ni et al. Human Capital, Innovation Capacity and Quality of Economic Growth - Based on Chinese Provincial Panel Data from 2000 to 2013. Global Journal of Management and Business Research. 2015, 14(8): 41-45.

[26] Grossman M. On the Concept of Health Capital and the Demand for Health. Journal of Political Economy, 1972, 80(2):223-255.

[27] Barro R J, Lee J W. International Measures of Schooling Years and Schooling Quality [J]. American Economic Review, 1996, 86(2):218223.

[28] Zhang Chewei. Nutrition, Health and Efficiency: Evidence from Poor Rural Areas in China [J]. Economic Research, 2003(1): 3-12.(in Chinese)

[29] Kesikoglu, Zafer ÖZTÜRK. Relationship between Human Capital and Economic Growth: Panel Causality Analysis for Selected OECD Countries. Journal of Economic \& Social Studies, 2013.
[30] Yu Changlin. Human Capital Investment Structure and Economic Growth - Based on the Theory of Endogenous Growth Mode Containing Educational Capital and Healthy Capital [J]. Journal of Finance and Economics, 2006, 32(10): 102-112. (in Chinese)

[31] Chu Chengbing, LI Ping. An Empirical Study on the Convergence of Educational Human Capital, Healthy Human Capital and Regional Economic Growth [J]. Journal of Guangxi Economic Management Cadre College, 2014, 26(01): 29-34+41. (in Chinese)

[32] Zhang Yuming, Liu Desheng. Research on the Relationship between Corporate Culture, Human Resources and the Growth of Small and Medium-sized Technology Enterprises [J].Science \& Technology Progress and Policy, 2010, 27(05):82-89. (in Chinese)

[33] Bresnahan T F, Brynjolfsson E, Hitt L M. Information Technology, Workplace Organization, and the Demand for Skilled Labor: FirmLevel Evidence [J]. Social Science Electronic Publishing, 2002, 117(1):339-376

[34] Wang Yijun, Zhang Weiying, Zhou Li'an. Information Technology, Organizational Change and Production Performance - An Empirical Study on the Phased Complementarity Mechanism of Enterprise Informatization [J]. Economic Research, 2006(01): 65-77.(in Chinese)

[35] Yao Dongmin, Ning Jing, Wei Shiyan. How aging affects technological innovation [J]. World Economy, 2017, 40 (04): 105128.(in Chinese)

[36] Ning Guangjie, Lin Ziliang. Information Technology Application, Enterprise Organizational Change and Labor Skill Demand Change[J] Economic Research, 2014, 49(08): 79-92.(in Chinese)

[37] Zhang Qian, Li Changying. The Direct and Indirect Effects of Informatization on Regional Innovation Performance - The Nonlinear Mediating Role of Human Capital [J]. Modern Economics Research, 2019(02): 113-121..(in Chinese)

[38] Li Linhan, Tian Weimin. Research on the relationship between technology finance, human capital and technological innovation Evidence from provincial panel data in China [J]. Science and Technology Promotion, 2019, 15(01): 26-35.(in Chinese) 